\title{
The effect of grazing different pasture herbage masses on rumen pH in lactating dairy cows
}

\section{E. Lewis ${ }^{1}$, F. Coughlan ${ }^{1}$, M. O'Donovan ${ }^{1}$, C. Wims ${ }^{1,2}$}

${ }^{1}$ Teagasc, Moorepark Dairy Production Research Centre, Fermoy, Co. Cork, Ireland

${ }^{2}$ School of Agriculture, Food Science and Veterinary Medicine, UCD, Belfield, Dublin 4, Ireland

Email:eva.lewis@teagasc.ie

Introduction The optimal use of grazed grass is identified as a key component of profitability in Irish dairy production systems (Shalloo et al., 2004). Pre-grazing mass, also known as herbage mass, affects herbage quality and is one factor that can influence herbage intake (DMI) at grazing. O'Donovan and Delaby (2008) illustrated that swards with higher herbage mass reduced the feeding value of grass and thus reduced DMI. However, it is also suggested that grazing high quality pastures can lead to low rumen $\mathrm{pH}$ (Gibbs et al., 2007). Rumen $\mathrm{pH}$ is cited as an important factor related to milk fat $\%$, fibre degradation, nutrient absorption and overall cow health and welfare (Kleen et al., 2003). Unfortunately, most of the information on rumen $\mathrm{pH}$ derives from work done with feeding high grain diets. Little information is available on the rumen $\mathrm{pH}$ of grazing dairy cows. Hence, the objective of the current study was to investigate the effects of three different herbage mass treatments on dairy cow rumen $\mathrm{pH}$.

Material and methods A systems study with three separate farmlets was established at the Teagasc Moorepark research farm and 20 dairy cows were allocated to each treatment. The three treatments were i) low herbage mass [LM] (1200kg $\mathrm{DM} / \mathrm{ha})$, ii) medium herbage mass $[\mathrm{MM}](1600 \mathrm{~kg} \mathrm{DM} / \mathrm{ha})$ and iii) high herbage mass $[\mathrm{HM}](2200 \mathrm{~kg} \mathrm{DM} / \mathrm{ha})$. The treatments operated for the duration of the grazing season (Apr-Oct). Stocking rates (2.9cows/ha) and post-grazing sward heights $(4 \mathrm{~cm})$ were the same for all three treatments. Grass was allocated on a daily basis and no supplementary feed was offered. All cows were milked twice daily. Six lactating rumen-cannulated dairy cows were arranged into two $3 \times 3$ latin squares and allocated to each treatment for one period each of two weeks. The study was carried out in the autumn part of the grazing season (Aug-Oct). Rumen $\mathrm{pH}$ was measured on days 10 and 11 of each period by means of an indwelling rumen $\mathrm{pH}$ probe. The Ionode IJ44 $\mathrm{pH}$ probe (Ionode Pty Ltd., Australia) was maintained immersed in one location at the bottom of the rumen by utilising a $1.5 \mathrm{~kg}$ stainless steel weight (Flyco, Ireland). The data were logged at 60 -second intervals over the 48-hour period using a Delta Ohm HD 2105.2 datalogger (Delta Ohm S.r.l., Italy) which was strapped to the cow's back using a MuPack backpack (Cassidy Covers, Ireland) and which was connected to the $\mathrm{pH}$ probe via a $2 \mathrm{~m}$ cable passing through a modified cannula bung (Bar Diamond, Inc., USA). Average rumen $\mathrm{pH}$ across the day was calculated, as was the amount of time spent below certain $\mathrm{pH}$ thresholds (see table). The data were analysed as a $3 \times 3$ latin square using the mixed procedure (PROC MIXED) of SAS with herbage mass treatment, experimental period, square, cow and their interactions included in the model.

Results There was no difference in the average ruminal $\mathrm{pH}$ of dairy cows when grazing grass of three different herbage masses. In addition, no effect of treatment was found on the amount of time during which rumen $\mathrm{pH}$ was less than $\mathrm{pH} 5.2$, $\mathrm{pH} 5.5$ or $\mathrm{pH} 5.8$. In comparison to data derived from lactating dairy cows on total mixed ration-type diets, it appears that the rumen $\mathrm{pH}$ of grazing dairy cows could be lower and the time they spend below certain thresholds greater. For example, Nocek et al. (2002) found that lactating dairy cows fed a total mixed ration diet spent $120 \mathrm{mins} / \mathrm{d}$ below pH5.5. However, the data presented here do agree with the low $\mathrm{pH}$ values suggested by Gibbs et al. (2007) for grazing dairy cows.

Table 1 The effect of grazing different pasture herbage masses on rumen $\mathrm{pH}$ in lactating dairy cows

\begin{tabular}{llllll}
\hline \hline & LM & MM & HM & s.e. & Significance \\
\hline Average rumen $\mathrm{pH}$ & 5.90 & 6.09 & 5.98 & 0.057 & NS \\
Time spent at rumen $\mathrm{pH}<5.2($ mins $/$ d) & 37 & 0 & 52 & 37 & NS \\
Time spent at rumen $\mathrm{pH}<5.5$ (mins/d) & 187 & 43 & 216 & 46 & NS \\
Time spent at rumen $\mathrm{pH}<5.8$ (mins/d) & 518 & 288 & 360 & 62 & NS \\
\hline \hline
\end{tabular}

Conclusions In the current study herbage mass did not have an effect on dairy cow rumen $\mathrm{pH}$. Further work is needed to expand on the very limited data available for grazing dairy cows, and to explore the mechanisms by which the low $\mathrm{pH}$ values seen in grazing systems are attained without the concomitant and expected problems in terms of lameness and milk fat concentration. Such work could re-define the guidelines for rumen $\mathrm{pH}$ in the grazing dairy cow specifically.

Acknowledgements The authors gratefully acknowledge the Dairy Levy Research Fund for financial support, and the help and co-operation of John Paul Murphy and the Moorepark farm staff.

\section{References}

Gibbs, J., Laporte-Uribe, J., Trotter, C. and Noel, J. 2007. Journal of Dairy Science 90(Suppl. 1), 655 (Abstract).

Kleen, J.L., Hooijer, G.A., Rehage, J. and Noordhuizen, J.P. 2003. Journal of Veterinary Medicine Series 50 (8), 406-414.

Nocek, J.E., Allman, J.G. and Kautz, W.P. 2002. Journal of Dairy Science 85, 422-428.

O’Donovan, M. and Delaby, L. 2008. Livestock Production Science 115, 158-168.

Shalloo, L., Dillon, P., O'Loughlin, J., Rath, M. and Wallace, M. 2004. Grass and Forage Science 59, 157-168. 